\title{
ENTRE CHICAGO E SALVADOR: DONALD PIERSON E O ESTUDO DAS RELAÇÕES RACIAIS
}

Between Chicago and Salvador: Donald

Pierson and the sociology of race relations

Entre Chicago y Salvador: Donald Pierson

e los estúdios de relaciones sociales

MARCOS CHOR MAIO E

THIAGO DA COSTA LOPES

http://dx.doi.org/10.1590/\$2178-14942017000100007

Marcos Chor Maior é doutor em Ciência Política pelo Instituto Universitário de Pesquisas do Rio de Janeiro (IUPERJ), professor e pesquisador da Fundação Oswaldo Cruz (maio@fiocruz.br).

Thiago da Costa Lopes é licenciado em Ciências Sociais pelo Instituto de Filosofia e Ciências Sociais da Universidade Federal do Rio de Janeiro (IFCS-UFRJ) e doutorando em História das Ciências na Fundação Oswaldo Cruz. (lopes_47@hotmail.com).

Artigo recebido em 15 de dezembro de 2016 e aprovado para publicação em 2 de fevereiro de 2017. 


\section{RESUMO}

Este artigo analisa, de uma perspectiva histórica transnacional, a pesquisa sobre relações raciais desenvolvida pelo sociólogo norte-americano Donald Pierson na cidade de Salvador entre 1935 e 1937, que resultou na sua tese de doutorado defendida na Universidade de Chicago sob orientação de Robert Park. Partimos da hipótese de que a forma como o sociólogo apresenta e analisa o vasto material coletado na Bahia, assim como as proposições de caráter mais geral contidas em seu livro, somente adquirem significado quando se explicita, além dos diálogos com os cientistas sociais brasileiros, seu enquadramento conceitual subjacente, que remonta à agenda de pesquisas capitaneada por Robert Park.

Palavras-ChaVE: Donald Pierson, história transnacional, relações raciais, Escola Sociológica de Chicago, Robert Park.

\section{Abstract}

This paper analyses, from a transnational historical perspective, the study of race relations undertaken by American sociologist Donald Pierson in the city of Salvador, Bahia, between 1935 and 1937, as part of his PhD dissertation in the University of Chicago. We hold the hypothesis that the way Pierson conducts his analysis of the vast empirical material collected in Bahia, as well as his general propositions, can be fully grasped only if one takes into consideration both his dialogues with Brazilian social scientists and his underlying conceptual framework, linked to Robert Park's research agenda.

KeYwORDS: Donald Pierson, transnational history, race relations, Chicago School of Sociology, racism.

\section{RESUMEN}

Este artículo analiza, desde una perspectiva histórica transnacional, la investigación sobre relaciones raciales desarrollada por el sociólogo estadounidense Donald Pierson en la ciudad de Salvador, Bahía, entre 1935 y 1937, como parte de su tesis doctoral defendida en la Universidad de Chicago bajo la dirección de Robert Park. Sostenemos la hipótesis de que la manera en que Pierson realiza su análisis del vasto material empírico recopilado en Bahía, así como sus proposiciones generales, sólo se pueden comprender plenamente tomando en consideración no sólo sus diálogos con los científicos sociales brasileños, sino también su marco conceptual subyacente, vinculado a la agenda de investigación de Robert Park.

Palabras Clave: Donald Pierson, História transnacional, relaciones raciales, Escuela Sociológica, racismo. 


\section{INTRODUÇÃO}

$\mathrm{E}$ ste artigo analisa, de uma perspectiva histórica transnacional, a pesquisa sobre relações raciais desenvolvida pelo sociólogo norte-americano Donald Pierson na cidade de Salvador, Bahia, entre 1935 e 1937, que resultou na sua tese de doutorado defendida na Universidade de Chicago sob orientação de Robert Park. A tese, publicada pela University of Chicago Press em 1942 sob o título de Negroes in Brazil: a study of race contact at Bahia, foi vertida para o português em 1945, intitulando-se Brancos e pretos na Bahia: estudo de contato racial. Aventa-se a hipótese de que a forma como o sociólogo apresenta e analisa o vasto material coletado na Bahia, assim como as proposições de caráter mais geral contidas em seu livro, somente adquirem pleno significado quando se explicita, além dos diálogos com os cientistas sociais brasileiros, seu enquadramento conceitual subjacente, que remonta à agenda de pesquisas capitaneada por Robert Park, sociólogo que exerceu forte ascendência nas Ciências Sociais norte-americanas do período. Guiados pelo interesse em responder a um dos principais desafios postos para os setores liberais reformadores da sociedade americana, a saber, 0 modo como deveria ser levada a efeito a incorporação de negros e imigrantes à comunidade política nacional -, os sociólogos da Universidade de Chicago buscaram, mediante uma sociologia comparada, construir uma tipologia das formas de estruturação das relações raciais observadas ao redor do mundo a fim de identificar seus mecanismos causais subjacentes.

Uma análise transnacional do estudo de Pierson sobre as relações raciais na Bahia servirá para melhor situar historicamente sua obra, gestada em um momento de estreitamento das relações Brasil-EUA e de busca de laços de cooperação internacional por parte dos cientistas sociais de Chicago. Buscamos pôr em relevo os nexos que ligam sua pesquisa, a um só tempo, aos contextos intelectuais brasileiro e norte-americano, à semelhança dos estudos globais e transnacionais que têm enfocado o movimento de atores, objetos e ideias que perpassam e cruzam as fronteiras entre os países assim como as inter-relações entre fenômenos sociais e culturais situados em distintas regiões do mundo (Clavin, 2005; Akira, 2013).

Tratando-se de uma perspectiva ou ângulo de análise, a história transnacional tem buscado lançar um novo olhar sobre a trajetória das nações modernas, até então tidas como singulares ou excepcionais, como se fossem movidas exclusivamente por forças internas 
autóctones (Thelen, 1999; Tyrrell, 2009). Em se tratando da produção do conhecimento científico ocorrida no passado, estas abordagens vêm assinalando o papel fundamental da circulação internacional de atores e ideias e de redes conectando diferentes partes do globo (Secord, 2004; Sivasundaram, 2010). Em texto programático voltado especificamente para uma história transnacional das Ciências Sociais, Heilbron, Guilhot \& Jeanpierre (2008) apontaram a necessidade de revisão dos pressupostos metodológicos "nacionalistas" da historiografia tradicional, que tende a conceber correntes e tradições de pensamento como produto de contextos nacionais estanques e autorreferidos, destacando, em contrapartida, os fluxos transnacionais que constituíram a história daquelas disciplinas. Constitui um desafio para esta abordagem a análise do que os autores denominam "estrutura dissimétrica" dos espaços transnacionais de troca, exemplificada, no período do pós-Segunda Guerra Mundial, pela hegemonia crescente que os EUA vieram a assumir em termos de modelos investigativos e organizacionais (Idem: 157). No Brasil, na esteira dos debates em torno da necessidade de alargamento dos horizontes da teorização sociológica do Atlântico Norte ou de sua "desprovincialização" (Costa, 2006), esforços têm sido feitos no sentido de ampliar a moldura analítica da história da Sociologia no país, articulando-a a movimentos globais da produção sociológica do passado, como a crítica às matrizes anglo-americanas da teoria da modernização (Brasil Jr, 2011), ou explorando suas afinidades com sociologias que estiveram igualmente situadas na periferia do mundo (Maia, 2015).

Partindo da compreensão de que a circulação é parte indissociável do processo de construção do conhecimento científico, e não apenas um momento derivado (Raj, 2013), acreditamos que a análise das obras, quando acompanhada do exame das circunstâncias em que elas foram produzidas, pode evidenciar a teia de conexões nacionais e internacionais que as constitui. Argumentamos que, longe de ser o desdobramento exclusivo de vertentes sociológicas norte-americanas ou tão-somente a reafirmação de conhecidas teses do pensamento social no Brasil, o estudo Brancos e pretos na Bahia, de Donald Pierson, reflete o entrecruzamento de diferentes tradições intelectuais, por mais que estas desempenhem papéis distintos em seu interior, e traz as marcas da circulação de atores e ideias entre regiões e países.

Inicialmente, são abordadas a trajetória de Pierson e as circunstâncias que o conduziram de Chicago a Salvador, chamando-se a atenção para o interesse da Universidade de Chicago no estudo das relações raciais, o papel desempenhado por Robert Park no processo que fez da Bahia um laboratório de experiências sociais internacionalmente reconhecido como tal e a rede de intelectuais brasileiros que abriu caminho para as pesquisas de Pierson em território nacional. Em seguida, a análise se volta para o conteúdo da obra do sociólogo norte-americano, enfocando seus procedimentos de pesquisa e principais achados, que constituem 
um denso registro etnográfico das relações entre negros, mulatos e brancos em Salvador, ainda que, por vezes, coloquem em tensão as linhas interpretativas mais gerais de sua tese. Por fim, as principais matrizes de pensamento que informaram o trabalho de Pierson são evidenciadas, e seus pesos relativos analisados, na tentativa de tornar inteligível o empreendimento de pesquisa do aluno de Robert Park para além das visões convencionais, geralmente circunscritas a enquadramentos nacionais específicos, que nos legou a fortuna crítica de sua obra.

\section{A BAHIA NO CIRCUITO INTERNACIONAL DAS CIÊNCIAS SOCIAIS}

\section{A} pesquisa de doutorado realizada por Donald Pierson entre novembro de 1935, quando chegou a Salvador, e setembro de 1937, foi um marco da sua formação acadêmica sob os auspícios da Universidade de Chicago em 1927 (Pierson, 1987; Villa Nova, 1998).

Sob o patrocínio de grupos filantrópicos batistas e da Fundação Rockfeller, o Departamento de Sociologia da Universidade de Chicago havia sido criado em 1892. Seus cientistas sociais buscaram a articulação entre ensino e pesquisa empírica, privilegiando, na construção dos objetos de estudo, a vida social do entorno da universidade (Bulmer, 1984; Coulon, 1995; Valladares, 2005). Metrópole sob processo de industrialização, Chicago enfrentava, no início do século XX, um boom demográfico, recebendo sucessivas ondas migratórias de trabalhadores europeus e negros vindos do Sul. Ao choque de etnias, somavam-se o crime organizado, as gangues, as greves, a proliferação dos guetos e o aumento da pobreza, fenômenos percebidos, sob as lentes dos setores reformadores de orientação protestante, como sintomas de desorganização social (Chapoulie, 2001).

Em fins dos anos 1920, momento em que Pierson ingressou na Universidade de Chicago, esta já gozava de reputação consolidada no cenário acadêmico norte-americano, contando, em seus quadros, com pesquisadores como Robert Park, Ernest Burgess, George Herbert Mead, Robert Redfield, Louis Wirth, Herbert Blumer, William Ogburn, Ellsworth Faris, entre outros. A Divisão de Ciências Sociais recebia, então, estudantes de perfil social variado, constituindo um dos canais de ascensão para jovens de origem rural, negros e descendentes de imigrantes (Silva, 2012).

Um sentido decisivo para o curso da trajetória de Pierson foi impresso após a aproximação do sociólogo, então no início de seu doutoramento, com Robert E. Park, uma das principais referências das Ciências Sociais nos EUA, tanto pelas pesquisas que vinha coordenando desde os anos 1910, e que tinham lugar no espaço urbano da cidade de Chicago, quanto por sua atuação em importantes associações científicas, como a American Sociological Society, da qual havia sido presidente em 1925. Ao lado Ernest Burgess, Park era o autor do livro An 
introduction to the Science of Sociology (1921), obra chave na socialização dos estudantes nos modelos interpretativos das Ciências Sociais do período.

Park nutria especial interesse pelas relações raciais. No início do século $X X$, depois de ter participado da Congo Reform Association, ele havia trabalhado como assistente de Booker T. Washington, influente liderança negra que apostava na ascensão econômica da população negra norte-americana por meio da educação profissional como estratégia de inserção gradual destes segmentos no mundo dos direitos. Enquanto auxiliava Washington no Tuskegee Institute, escola normal e profissionalizante para negros do Alabama mantida por filantropos norte-americanos, Park empreendeu viagens de observação ao Deep South e a localidades rurais da Europa, ganhando uma visão comparativa das condições de vida dos negros nos EUA e dos camponeses europeus. Seu envolvimento com questões raciais o levou a ser convidado, em 1912, a ministrar cursos em Chicago sobre o tema, que se tornou um dos focos principais de seu programa de pesquisas nas décadas seguintes (Chapoulie, 2001). Percorrendo diversas regiões do globo, tais como Havaí, Japão, China, Índia e África do Sul, Park buscou ampliar seu escopo de análise sobre as relações raciais para além do território americano, perseguindo uma sociologia comparada das variadas formas de arranjo inter-étnico que se haviam cristalizado a partir do contato entre diferentes povos e culturas no âmbito da colonização europeia do mundo (Pierson, 1944; Valladares, 2010; Silva, 2012).

Park conseguiu atrair Pierson para o estudo dos problemas de contato racial e cultural no Brasil após retornar de extensa viagem ao redor do mundo no início dos anos 1930, momento em que esteve pela primeira vez no país (Pierson, 1944: 285). Na ocasião, Park estabeleceu contato com Oliveira Vianna e Arthur Ramos no Rio de Janeiro e adquiriu obras referentes ao Brasil, como Os africanos no Brasil, de Raimundo Nina Rodrigues.

A proposta para que Pierson estudasse o Brasil ocorreu durante o Seminar on Race and Cultural Contacts, ambicioso programa de pesquisas da Divisão de Ciências Sociais que se voltava para o mapeamento dos resultados das interações inter-étnicas ao redor do globo e cuja direção coube a Robert Park, Robert Redfield, Louis Wirth e Herbert Blumer (Pierson, 1941: 165). Nas palavras de Pierson, aquele grupo de pesquisadores tinha como objetivo "traçar a série de acontecimentos que estes contactos [raciais e culturais] põem em movimento, e descrever o ciclo de transformação social, assim precipitado. Nosso principal interesse consiste nestes ajustamentos que o contacto de uma cultura com outra ou de uma raça com outra tornam sempre imperativos" (Pierson, 1936: 92).

Em 1933, Pierson assumiu, perante o Social Science Research Committee da Universidade de Chicago, o compromisso de conduzir pesquisa no Brasil com recursos da Fundação Rosenwald. ${ }^{1}$ O estudo do sociólogo integrava um empreendimento coletivo internacional de 
investigações sob a batuta de Chicago que envolvia: trabalhadores negros de Chicago e do Sul Rural (H. Cayton), filhos de imigrantes japoneses na Costa Oeste dos EUA (F. La Violette), uma comunidade rural franco-canadense (H. Miner), um vilarejo no interior do Japão (J. Embree), diversas comunidades da Península de Yucatán, no México (R. Redfield), e o arquipélago do Havaí, com seus distintos grupos étnicos, de origem polinésia, europeia e asiática (A. Lind) (Pierson, 1941: 166). ${ }^{2}$

Além de Park, o antropólogo Robert Redfield e o sociólogo Louis Wirth também se envolveram na orientação das atividades de Pierson no Brasil, que, além do trabalho de campo, foi encarregado da dupla missão de sondar as possibilidades de pesquisas em Ciências Sociais no país e de estabelecer contato com setores da intelectualidade local que eventualmente pudessem contribuir para o estudo dos contatos de raça e cultura em escala transnacional. ${ }^{3}$ Em meados dos anos 1930, a Universidade de Chicago buscava ampliar sua rede de colaboradores para além dos EUA, de modo que a viagem de Pierson refletia os esforços de internacionalização e intercâmbio acadêmico da Divisão de Ciências Sociais. ${ }^{4}$

Antes de partir para o Brasil, e como parte de seu treinamento prévio para o estudo que devia realizar sobre a situação racial do país, Pierson atuou como assistente de Park em cursos que este passara a ministrar na Universidade de Fisk. Situada em Nashville, Tennessee, Fisk foi uma das instituições de ensino superior criadas para atender à população negra do Old South no bojo de iniciativas de grupos missionários protestantes que se seguiram à guerra civil americana. 0 convite para que Park ministrasse aulas em Fisk partira de Charles Johnson, que começara a lecionar na instituição em 1928, fundando o Departamento de Ciências Sociais, e estava em vias de concluir sua tese de doutorado sobre as comunidades negras das plantations sulistas sob orientação do sociólogo de Chicago. A partir de uma rede de ativistas negros, reformadores, antropólogos e sociólogos vinculados a diferentes instituições norte-americanas, o Instituto de Relações Raciais de Fisk conseguiu se estabelecer como um dos principais centros de estudo sobre raça e relações inter-étnicas dos EUA, frequentado, entre outros, por Franz Boas, Otto Klineberg, Rüdiger Bilden, Melville Herskovits e Franklin Frazier (Silva, 2012). Em 1935, Pierson ministrou aulas sobre o Brasil apoiando-se em suas leituras ${ }^{5}$ e, em seguida, participou de pesquisas no Sul rural desenvolvidas por Charles Johnson como parte dos planos de recuperação econômica da região implementados pelo New Deal, entrevistando operários, em sua maioria negros, nos Estados americanos de Virginia, Carolina do Norte e Kentucky (Pierson, 1987).

Após a experiência de pesquisa sobre populações negras, Pierson partiu de New Orleans em direção ao Rio de Janeiro. Aportou em julho de 1935, travando contato, entre outros, com Oliveira Vianna, Gilberto Freyre, Arthur Ramos e Anísio Teixeira. Em São Paulo, conheceu 
o sociólogo Samuel Lowrie, da Escola Livre de Sociologia e Política (Pierson, 1987: 37-39). 0 encontro com estes intelectuais, especialmente com Arthur Ramos, foi decisivo para a pesquisa do sociólogo, que se apoiou em uma rede de informantes e mediadores que se estendia pelos diferentes círculos sociais de Salvador, como as elites políticas, os escritores e as comunidades dos terreiros de candomblé (Idem). Durante os 22 meses de sua permanência em Salvador, Pierson residiu em pontos distintos da cidade: em áreas da classe média como Vitória, Barra e Mercê, e nas proximidades do Engenho Velho e Gantois, onde parte da população pobre então residia. Em Matatu Grande, o sociólogo foi iniciado nos rituais do candomblé pelo pai-de-santo Procópio d'Ogum (Idem).

Antes do término de sua pesquisa, Pierson recebeu a visita de Robert Park, que permaneceu em Salvador entre julho e agosto de 1937, explorando a cidade e travando contato com seus habitantes (Valladares, 2010). Em fins daquele ano, Pierson retornou aos EUA. Instalando-se na residência de Park em Nashville, ele conduziu, ao lado do antigo professor, um seminário sobre raça e cultura na Universidade de Fisk enquanto redigia sua tese (Pierson, 1987).

A pesquisa de Pierson contribuiu para colocar a Bahia no circuito internacional das Ciências Sociais, e as redes que teceu conjuntamente com Park foram acionadas nos anos subsequentes por pesquisadores americanos que fizeram viagens de estudo à região, como Ruth Landes e Franklin Frazier (Valladares, 2010; Sansone, 2012). 0 estudo sobre a Bahia teve desdobramentos posteriores na carreira do sociólogo. Contratado para lecionar na Escola Livre de Sociologia e Política de São Paulo em 1939, Pierson atuou na construção do campo acadêmico das Ciências Sociais no Brasil, buscando imprimir-Ihe as marcas de Chicago (Limongi, 1989; Vila Nova, 1998). Em um período em que a diplomacia cultural, especialmente o intercâmbio e as trocas científicas, tornou-se instrumental para a política norte-americana na América Latina em face da crescente presença alemã na região (Mulcahy, 1999; Freire Junior \& Silva, 2014), o sociólogo se tornou um dos mediadores no esforço de aproximação diplomática entre EUA e Brasil (Maio et al., 2013). ${ }^{6}$

\section{A TESE DE PIERSON SOBRE AS RELAÇÕES RACIAIS NA BAHIA}

A bert Park, que considerava o Brasil como um laboratório racial. Ele busca compreender os efeitos do contato entre as raças na região, supondo que, em meio a disputas por recursos e espaço que a concentração de populações distintas em um mesmo habitat inevitavelmente colocava em marcha, arranjos sociais mais ou menos estáveis tendiam a se cristalizar a fim 
de pôr termo ao conflito aberto ou reduzi-lo a um mínimo suportável, atribuindo nichos de atividade e papeis específicos às raças, distribuídas hierarquicamente, ou fundindo-as em uma nova unidade étnico-cultural. Pierson conduz sua pesquisa na Bahia a partir desta perspectiva, que postula que as relações raciais devem ser analisadas à luz dos processos de competição, conflito, acomodação e assimilação (Park \& Burgess, 1921: especialmente os capítulos 8 a 11; Pierson, 1945b).

A gênese do esquema conceitual proposto por Robert Park remonta à experiência racial norte-americana posterior à Guerra de Secessão, marcada pela segregação racial institucionalizada no Sul, a suspensão dos direitos políticos dos negros, a proibição do casamento inter-racial e o acirramento das tensões étnicas nas cidades do Norte, decorrente da migração em massa da população rural. Importante para se compreender a perspectiva sociológica de Park é o conceito de assimilação, que adquire inteligibilidade quando se considera o horizonte normativo dos sociólogos e reformadores atuantes na cidade de Chicago, que se interrogavam pelas possibilidades de integração dos negros e das demais minorias étnicas à "sociedade americana", concebida como unidade sócio-política organizada segundo os valores da cultura anglo-saxônica protestante (Chapoulie, 2001: 315-320).

A fim de avaliar o grau de integração do negro à sociedade baiana, cuja matriz cultural dominante é identificada à do colonizador português, Pierson se pergunta se a cor constituía critério de estratificação social em Salvador e em que medida as raças formavam grupos ocupacionais endogâmicos, ou ainda, o grau de porosidade racial dos estratos sociais, lançando mão do par conceitual "casta" e "classe", que vinha sendo utilizado por cientistas sociais em estudos do Sul rural americano sob a orientação de W. Lloyd Warner. Na conceituação de Pierson, enquanto o conceito de classe social indica a existência de camadas abertas, permeáveis à mobilidade vertical, a casta é pensada, por oposição, como camada fechada cujos membros são determinados por nascimento e sobre os quais necessariamente se impõem fortes sanções ao casamento fora do grupo (Pierson, 1945b: 442-458). Esta forma de tratar operacionalmente das relações raciais foi sugerida por Park ainda no início do trabalho de campo de Pierson, então às voltas com a seleção e a interpretação do material empírico. Park pondera que: "[...] parece que você tem na Bahia, assim como nós aqui nos Estados Unidos, uma combinação de sistemas de classe e casta ou uma situação em que a classe está substituindo a casta. Cada raça, incluindo os mestiços [mixed bloods], contanto que tenha um nome ou algum grau de autoconsciência, tende a estar representada em todas as classes ocupacionais. Mas o grupo racial que apresenta status superior terá proporcionalmente números maiores nos estratos superiores enquanto os grupos raciais que apresentam status inferior terão números maiores nos estratos inferiores $[\ldots]^{\prime \prime}$. 
No intuito de verificar estas hipóteses, Pierson lançou mão de diferentes recursos de pesquisa: levantamento de dados censitários e de fontes arquivísticas em instituições públicas; elaboração de amostras próprias da composição racial de diferentes ocupações, associações e bairros da cidade, e aplicação de questionários em instituições de ensino visando à sondagem das atitudes raciais de jovens estudantes. Seu trabalho de cunho mais etnográfico envolveu a realização de entrevistas e a observação participante, por meio das quais buscou avaliar 0 grau e a forma de participação das raças em diversas atividades sociais de Salvador. Pierson ainda reuniu "histórias de vida" de personalidades negras ocupando distintas posições na sociedade baiana por meio de textos autobiográficos e correspondências, recurso metodológico consagrado nas Ciências Sociais de Chicago desde os estudos de W. Thomas e F. Znaniecki sobre o imigrante polonês nos EUA.

A conclusão a que Pierson chega é a de que a cor do indivíduo tinha pouco peso na determinação de sua posição social quando comparada a outros atributos como riqueza, educação e observação de certos padrões de etiqueta, de modo que critérios raciais não eram decisivos na organização da vida social local. Embora comumente assinalada pelos críticos e estudiosos, tal interpretação sociológica, em chave "classista", nem sempre condiz com os elementos que emergem da pesquisa de Pierson, especialmente de seu trabalho etnográfico, que por vezes acabam desestabilizando as afirmações de ordem mais geral do sociólogo ao indicarem as fortes conotações negativas associadas à cor e as tensões daí advindas. Antes porém de nos atermos às interpretações que se cristalizaram em torno da obra de Pierson, que tendem a concebê-la como uma ratificação da tese da democracia racial e a desconsiderar 0 encontro transnacional de ideias que está em sua origem, buscaremos ressaltar, a partir de uma análise atenta de Brancos e pretos na Bahia, o modo como o sociólogo constrói sua narrativa e as incongruências que surgem entre esta e o material empírico apresentado.

Inicialmente, Pierson lança uma visão geral sobre a Bahia, classificando-a como uma sociedade tradicional, patriarcal, de base rural e sob forte influência católica, o que não implicava, a seu ver, ausência de mudanças sociais, assinaladas ao longo do livro. Tratava-se de uma sociedade "relativamente isenta das diversas formas de conflito", como as que opunham capital e trabalho ou as raças (Idem: 62-63). Tensões raciais, todavia, emergem já no segundo capítulo do livro, momento em que, à maneira dos estudos em ecologia humana de Chicago (Eufrásio, 1999), Pierson analisa a distribuiçãa residencial da população local segundo a cor: "[...] à primeira vista, a Bahia faz lembrar uma cidade medieval cercada por aldeias africanas" (Pierson, 1945: 72). As periferias são ocupadas majoritariamente por negros ao passo que os brancos se concentram nas áreas nobres, havendo espaç̧os de transição, em que negros, mulatos e brancos residiam lado a lado. As exceções representadas pelos residentes negros e 
mulatos dos bairros de classe média, e pelos habitantes brancos das áreas pobres, permitem a Pierson sustentar a tese de que a divisão espacial das raças é resultado da competição econômica, e não de segregação institucionalizada, sendo a posição desvantajosa do negro decorrência da antiga condição escrava. Isto não o impede de indicar que, de um total de 142 jovens brancos, 22 expressavam incômodo com a possibilidade de ter vizinhos negros alegando que estes viriam a comprometer o status do bairro (Idem: 77).

Pierson se volta, em seguida, para o processo histórico que conduziu àquele estado de coisas. Recorrendo às obras de autores brasileiros como Gilberto Freyre, Luiz Anselmo da Fonseca, Nina Rodrigues, Pedro Calmon e Arthur Ramos, além de relatos de cronistas do século XIX, como Henry Koster, Maria Graham, John Codman e Richard Burton, o sociólogo trata da história da escravidão africana na Bahia, que resultou, a seu ver, na dependência mútua, para fins de sobrevivência, entre as raças. 0 tráfico de pessoas, provenientes principalmente de Angola e Guiné, visava à economia agroexportadora baseada no latifúndio implantada pelos portugueses. Em praticamente um terço deste capítulo (12 de 46 páginas), Pierson se ocupa em registrar diversas insurreições de escravos ocorridas na Bahia do século XIX, assim como episódios de fuga e castigo corporal (Idem: 93-105). Embora Pierson enfatize a brandura da escravidão, seu quadro é mais complexo ao trazer casos de violência, que se evidenciam principalmente na repressão a revoltosos, identificados ou com os escravos das lavouras, distantes do convívio com os senhores, ou com os africanos de origem islâmica relativamente instruídos, que se opunham ao catolicismo e não se deixavam assimilar facilmente. Apoiando-se em Gilberto Freyre, Pierson trata da progressiva transformação da escravidão, de instituição econômica formal, em um tipo de relação pessoal, de dominação patriarcal e benevolente, entre senhor e escravo; transformação esta operada graças à proximidade dos contatos no interior da casa grande e à criação de laços de solidariedade mútua, o que favoreceu a assimilação do negro à cultura europeia e o enfraquecimento das barreiras de casta entre as raças (Idem: 135). A abolição foi o termo deste processo de mudança gradual, marcado pela adesão da sociedade brasileira, afeita à prática da alforria e contando com um número crescente de negros e mulatos livres, à vaga emancipatória, que não representou uma ruptura drástica com a ordem estabelecida nem desencadeou conflitos à semelhança da guerra civil americana.

Explorando fontes arquivísticas, Pierson analisa, na sequência, o histórico da miscigenação e do casamento inter-étnico no país. Partindo de uma análise ecológica, o sociólogo afirma que, assim como alhures, a mistura se processou a fim de atender imperativos práticos da colonização, que exigia, na ocupação dos territórios, uma base populacional mínima. À falta de mulheres brancas, o intercurso sexual com nativas foi tolerado pelos portugueses. No Brasil, entretanto, esta prática se tornou hábito e, com o tempo, traço da cultura nacional, 
não encontrando, à diferença de outros contextos coloniais, como o sul-africano e 0 indiano, circunstâncias adversas que Ihe perturbassem a evolução (Idem: 180-1). Os brancos também se amalgamaram com os negros. 0 caráter extralegal dessas uniões, o concubinato, não causa porém estranheza a Pierson, que atribui o fato ao aumento da oferta de mulheres brancas ao tempo da entrada das primeiras levas de africanos nas colônias.

Pierson constata que a disposição para a mistura étnica permanecia no presente, condicionada, entre outros fatores, pela instituição da empregada doméstica, que mantinha brancos e negros em contato íntimo, e pelo desejo generalizado de contrair relações com brancos. Em uma maternidade pública, o sociólogo registra o orgulho das mães mulatas que exibiam seus bebês de pele mais clara. Segundo Pierson, era comum, nessas situações, ouvir-se a declaração: "Não quero voltar para a África" (Idem: 182). Assim, as "circunstâncias favoráveis à miscigenação" (Idem: 180) analisadas por Pierson acabavam por acentuar o status inferior do negro e a depreciação sistemática de seus traços fisionômicos, elementos identificados pelo sociólogo mas que permanecem laterais em sua reflexão.

0 mesmo se observava em relação ao fenômeno do casamento inter-racial, em que a cor branca constituía moeda de troca valorizada. Pierson nota que, do total de uniões legais ocorridas entre 1 de setembro de 1933 e 31 de dezembro de 1934, apenas 3,3\% envolviam casamento inter-racial. Enfocando os poucos casos identificados de inter-casamento, o sociólogo observa que estes em geral envolviam uniões no interior de uma mesma classe. Quando os parceiros provinham de classes diferentes, o branco tendia a se beneficiar economicamente da união, sendo o cônjuge negro mais bem-sucedido financeiramente. Nas raras situações em que o negro se beneficiava da vantagem econômica, o parceiro branco tendia a ser mulher, "circunstância que [...] era de esperar-se, numa sociedade em que as mulheres estão [...] em desvantagem social e, ao mesmo tempo, sofrem pressão para evitar o celibato" (Idem: 211). Pierson ainda se defronta com fortes objeções ao casamento inter-racial por parte da elite: "Se alguém se casa com pessoa bem mais escura, ouve-se dizer: 'Ele não tem vergonha na cara'" (Idem: 212).

Em um movimento característico, Pierson relativiza o peso da cor no estabelecimento de relações matrimoniais, indicando que as atitudes adversas aos negros se voltavam mais contra a classe do que a raça. A chave classista é acionada na interpretação das razões fornecidas por estudantes brancos em sua recusa, quase unânime, em se casar, e mesmo dançar, com negros: "são rudes e ignorantes" ou "não possuem representação social". Nem todas as respostas, entretanto, se encaixam facilmente neste esquema interpretativo, e por vezes sugerem atitudes francamente racistas: "Porque os acho inferiores, intelectual e socialmente, e não me sentiria bem em sua convivência" (Idem: 215). 
Após analisar como a miscigenação se processava, Pierson se volta para os seus efeitos, a começar pela redução das diferenças físicas entre as raças (Idem: 185). Pierson registra a crença difundida acerca do branqueamento da população, indicado com orgulho por brancos e mulatos, e se pergunta por seus fundamentos. Assinala, como hipótese explicativa para esta crença social generalizada, a redução gradativa do número de negros na população total, uma vez que, dadas suas precárias condições de vida, sobre eles incidia a maior taxa de mortalidade infantil. Indica ainda a possibilidade de inflação do número real dos brancos, considerando-se a plasticidade desta categoria, que tendia a incluir muitos mestiços de pele clara, fenômeno comum que era expresso pelo ditado: "Quem escapa de negro, branco é" (Idem: 190). Pierson nota, a esse respeito, que as classificações raciais nativas operavam a partir da aparência física, levando em conta principalmente a textura do cabelo e a cor da pele, e diferiam da categorização norte-americana, produtora de divisões raciais estanques porque baseada na ascendência racial.

À falta de dados censitários precisos, Pierson buscou conhecer a composição racial da população de Salvador com base em observações diretas do evento público que mobilizava toda a cidade, a Micareta. Classificando os indivíduos conforme sua "origem étnica", ele constatou que sua esmagadora maioria era constituída por mestiços, havendo poucos brancos e africanos "biologicamente 'puros'" (Idem: 192). 0 resultado desta amostragem, todavia, dificilmente poderia, por si só, justificar ou dar respaldo à hipótese de Pierson segundo a qual os negros vinham sendo crescentemente incorporados biologicamente aos mulatos e estes, aos brancos (Idem: 392), conclusão a que o sociólogo chega, ao que tudo indica, em razão da leitura de autores que, como Oliveira Vianna, enxergavam no branqueamento o sentido do processo de miscigenação no Brasil. Pierson se apoia em uma visão em torno da qual havia relativo consenso no contexto intelectual brasileiro.

No âmbito das relações sociais, a miscigenação tivera como efeito a produção de laços de solidariedade no interior das famílias que cruzavam as linhas de cor, inibindo o fortalecimento do "preconceito de casta" (Idem: 195). Isto possibilitou, no século XIX, pari passu ao florescimento das cidades e à decadência das antigas aristocracias rurais, a ascensão social dos mestiços, que, obtendo vantagens junto aos senhores em termos de proteção familiar e formação educacional, vieram a se perfilar entre as novas categorias urbanas dos profissionais liberais, doutores e bacharéis, assumindo por vezes posições de destaque no mundo das artes, das ciências e da política. A análise de Gilberto Freyre acerca da ascensão do mulato fornece a Pierson a chave para compreender a transição da antiga ordem escravocrata, organizada em castas, para uma sociedade de classes. Penetrando nas camadas superiores, individual e gradativamente, o mulato teria contribuído para minar a hierarquização dos grupos sociais 
segundo linhas de cor, preparando o advento de um tipo de estratificação social formado por camadas abertas em que a raça tendia a assumir papel secundário na determinação do status. Voltando-se para a estratificação social da cidade de Salvador no presente, Pierson observa a distribuição desigual de negros, mulatos e brancos nas diferentes classes, que 0 sociólogo define segundo suas ocupações, poder aquisitivo e prestígio social. Em 1936, de um total de 232 indivíduos exercendo o cargo de professor universitário, 70,3\% eram brancos e $14,2 \%$, mulatos. Não havia padres negros, nem bancários, nem negociantes, sendo os negros somente $1 \%$ dos médicos e $1,7 \%$ dos políticos e advogados. Por outro lado, não havia estivadores brancos, nem lavadeiras, carroceiros ou pedreiros. Do total destas amostras, 93\%; $89,5 \% ; 83 \%$ e $82,4 \%$ eram, respectivamente, compostas por negros (Idem: 241-5). Não havia negros entre os membros do clube da elite baiana, existindo, entre os não brancos, apenas alguns mulatos (Idem: 249). Nas escolas, o número de alunos negros era limitado, havendo "progressiva eliminação das cores mais escuras à medida que se sobe na escala educacional" (Idem: 250).

Em que pese o quadro de desigualdades raciais apreendido por Pierson, o sociólogo afirma que a concentração da população negra na base da pirâmide social, longe de refletir uma rígida estrutura, era o resultado previsível do curto espaço de tempo transcorrido desde a abolição. Em seu esforço ascensional, o negro tivera que partir dos níveis sociais e econômicos mais baixos. Pierson reconhece que a cor podia significar uma desvantagem na competição por status, símbolo indelével da origem escrava, mas insiste em afirmar que ela não constituía obstáculo insuperável, nem selava, em definitivo, o destino social do indivíduo: "Sem dúvida, a cor é um percalço. Mas tende sempre a ser esquecida, se o indivíduo em questão possuir outros característicos que identificam as classes 'superiores', tais como competência profissional, capacidade intelectual, educação, riqueza, encanto pessoal, pose, e, especialmente para as mulheres, beleza" (Idem: 268). Ao afirmar que as posições sociais não eram fixas, e que atributos de classe eram mais decisivos do que a cor na determinação do status, Pierson se apoia sobremaneira na trajetória de mulatos que, ascendendo socialmente, haviam não apenas conquistado melhor condição financeira, como a classe média negra americana, mas também penetrado, à diferença desta, nos círculos das elites, sendo reconhecidos por toda a comunidade.

As tensões entre a leitura sociológica de Pierson, em chave classista, e os resultados de sua pesquisa chegam ao paroxismo no momento em que aborda, em rico registro etnográfico, o que pensavam e como agiam negros, mulatos e brancos uns em relação aos outros. Pierson se defronta com "atitudes de descontentamento e protesto" (Idem: 285) e sentimentos de "exploração" e "incompreensão", especialmente por parte dos negros (Idem: 290), revelando 
situações em que a cor constituía fonte de conflitos, constrangimentos e adversidades na vida daqueles sujeitos.

Em documento intitulado "O negro na Bahia", escrito, a pedido do sociólogo, por um estivador negro, o autor observa que as elites brancas baianas se comportavam com prepotência e senso de superioridade, criando barreiras à oportunidade de elevação na profissão por parte da população negra, considerada inferior e privada de qualquer reconhecimento social (Idem: 287-288). Os brancos, por seu turno, mantinham atitudes que variavam da indiferença à "indulgência" em relação à "massa dos pretos" (Idem: 289).

Pierson considera ainda as atitudes dos mulatos, que demonstravam forte obstinação em branquear-se. Dialogando com o conceito de "homem marginal", categoria cunhada por Park que teve desdobramentos na obra de Everett Stonequist, o sociólogo sugere que a personalidade dos mulatos em ascensão era marcada por ambivalências decorrentes de sua inscrição em mundos sociais distintos (Idem: 237). Eles se esforçavam por ocultar a ascendência africana e a origem escrava, comportamento registrado de modo significativo nos versos do poeta popular João Varella: "Do pai branco, que nunca viu/ Tem o retrato na sala;/ Mas... da preta que o pariu/ Não tem retrato, nem fala" (Idem: 291).

Pierson observa que o movimento ascensional produzia fricções. Homens da elite baiana consideravam os empregados negros preferíveis aos mulatos, percebidos como desonestos, excessivamente ambiciosos, "sem caráter", "sempre procurando ser mais brancos do que são" (Idem: 294-5). Estas atitudes, todavia, não são interpretadas na chave do "conflito racial", uma vez que, na visão do sociólogo, "pretos e brancos não se defronta[vam] como grupos étnicos irredutíveis, diferentes não só na aparência [...], mas também em natureza, e destinados a ficar para sempre separados e distintos" (Idem: 281-282).

A tradução do conflito em termos de classe, todavia, se choca com situações em que aquele assume expressões racializadas. É o caso de uma cozinheira negra que, encolerizada, se dirige a um mulato: "Escute, sabido, você é apenas um mulato sujo! Nem sequer pertence a uma raça pura! Antes quero ser preta que mestiça!" (Idem: 292). Pierson registra ainda o desabafo de um homem negro que se zangara com um mulato: "Muito bem! É isto que a gente recebe de um mulato. Misturar as raças sempre dá numa cousa destas" (Idem: 292).

Ao analisar as agressões verbais sofridas por negros, geralmente em confrontos face a face, quando a cor vinha à tona, Pierson não Ihes atribui qualquer significação racial, lendo-as como choques ou de nacionalidades ou de culturas derivados, em ultima análise, do etnocentrismo: "Se um baiano quiser ser particularmente injurioso, agravará a picada constituída pela palavra 'negro' acrescentando-lhe 'da África', acentuando, assim, duplamente sua alusão à origem estrangeira do preto" (Idem: 282). A minoria negra praticante do culto aos orixás era 
particularmente suscetível, neste sentido, a atitudes adversas, ainda que, conforme o juízo do sociólogo, predominasse, entre os brancos, a postura tolerante e paternalista. A oposição ativa era, contudo, visível nas queixas que chegavam aos jornais, solicitando medidas repressivas das autoridades contra a prática do candomblé nas vias públicas da cidade, percebida como ameaça aos foros civilizados (Idem: 378-380). As reações de insatisfação dos negros identificados com a tradição africana são interpretadas, por seu turno, como sinal de ressentimento diante da assimilação crescente à cultura dominante, de matriz europeia, processo considerado inexorável por Pierson: "Se eu vir um africano agradando um desses brancos, não olharei para o branco, mas olharei o preto de alto a baixo, assim (deu à face uma expressão de desprezo, de desdém) e quando passar farei sempre assim (pigarreou fortemente e cuspiu)" (Idem: 335). A este depoimento, o sociólogo acrescenta o relato de um homem branco que, passeando em companhia de "um velho feiticeiro [negro] e seu filho" pela Ladeira da Cruz da Redenção, ouviu de um morador negro, que punha a cabeça para fora da janela de seu casebre: "Que negros! Trastes! Andando com branco!" (Idem: 336).

A forma como Pierson interpreta seus resultados de pesquisa decorre dos problemas que se coloca, que somente ganham sentido a partir do esquema teórico-conceitual no interior do qual o sociólogo se move. As tensões e os conflitos entre negros, brancos e mulatos, as manifestações de insatisfação e a difícil aceitação de casamentos com negros não deviam, a seu ver, ser superestimados na avaliação do quadro geral das relações raciais em Salvador. Importante, a esse respeito, era notar que o encontro das raças na região, à diferença dos EUA, da África do Sul e da Índia, desencadeara um processo de miscigenação étnica que transcorrera de maneira ininterrupta ao longo da história, cristalizando-se em uma cultura miscigenacionista e possibilitando, a partir dos contatos íntimos no interior das famílias, o estabelecimento de laços de solidariedade inter-raciais. Prova disto, segundo Pierson, era que a raça tinha pouca relevância para a estratificação da sociedade baiana, estando negros, mulatos e brancos representados em todas as ocupações, ainda que de maneira desigual, e havendo ainda a possibilidade de ascensão e reconhecimento social dos indivíduos de cor pela comunidade como um todo. Dada a "disseminada teia de relações pessoais na Bahia" (Idem: 282), os indivíduos tendiam a ser considerados a partir de seus contatos em uma extensa rede de amigos e parentes, dificilmente sendo percebidos a partir de categorias raciais substantivas e estanques. Embora implicando o estigma da escravidão, as marcas raciais perderiam gradativamente esta significação à medida que, por um lado, a mistura étnica prosseguisse, resultando no branqueamento da população, e, por outro, um número crescente de mulatos e negros, galgando a pirâmide social, atestassem suas capacidades e méritos pessoais. As hipóteses de Pierson convergiam para a tese segundo a qual a Bahia constituía, ao lado do Havaí, uma sociedade 
multirracial de classes, distanciando-se tanto da situação norte-americana, em que uma classe média negra ascendia apenas no interior de sua comunidade, não sendo aceita pelos brancos em condições de igualdade formal, quanto do caso extremo da sociedade de castas indiana.

\section{UMA OBRA TRANSNACIONAL}

leitura sociológica de Pierson, em chave classista, dos constrangimentos sofridos por
negros e mulatos, e das tensões e conflitos que emergem no cotidiano, é controversa quando confrontada com os depoimentos e casos registrados em campo pelo sociólogo, que assumem expressões por vezes bastante racializadas. Os elementos que resultam do seu rico trabalho etnográfico se põem em tensão com suas hipóteses e conclusões mais gerais, prestando-se a leituras alternativas. As incongruências entre o material empírico e a linha interpretativa adotada por Pierson foram notadas em resenha à edição norte-americana realizada pelo antropólogo Joseph Bram, formado na Universidade de Columbia, que as converteu, talvez não sem ironia, em ponto a favor da objetividade do trabalho do sociólogo: "[...] 0 autor não hesitou em disponibilizar materiais que enfraquecem seu próprio argumento e em fornecer munição contra suas próprias visões" (Bram, 1944: 544). ${ }^{8}$

No Brasil, todavia, tornou-se recorrente, deixando-se de lado as nuances e tensões no interior da obra de Pierson, associar a pesquisa do sociólogo a uma visão edulcorada das relações raciais no país, espécie de reiteração, conforme as interpretações convencionais da obra de Gilberto Freyre, do mito da democracia racial (Hasenbalg, 1995), ou à negação categórica de quaisquer formas de preconceito e discriminação ligadas à cor (Guimarães, 2004). A Bahia que salta do retrato etnográfico matizado de Pierson, todavia, dificilmente se traduz em um mundo idílico de harmonia racial. ${ }^{9}$

A primeira edição brasileira do livro de Pierson (1945) e sua recepção posterior no país contribuíram sobremaneira para esta leitura, "nacionalizando" sua obra, colocando-a em continuidade com tradições intelectuais locais, e destacando, como conclusão fundamental a se reter, a confirmação da ausência de preconceito de raça no país. Este foi o espírito do prefácio de Arthur Ramos. Após observar que "os estudiosos brasileiros viviam escrevendo sobre a inexistência, entre nós, de preconceitos de raça, julgando assim o Brasil o país ideal neste plano da coexistência harmônica de povos e raças de vários matizes étnicos" (Ramos, 1945: 22), Ramos destaca que Pierson havia chegado "às mesmas conclusões que estavam admitidas [...] tradicionalmente" (Idem: 23). Restava, como questão aberta à discussão, saber "se este preconceito ligado à cor negra mais carregada coincid[ia] ou não com o status social e econômico mais baixo" (Idem: 24). Nos anos 1950, sociólogos que participaram do Projeto 
Unesco de Relações Raciais, como Roger Bastide, Florestan Fernandes, Oracy Nogueira e Luiz de Aguiar Costa Pinto tornaram a pôr em evidência, na leitura da pesquisa de Pierson, suas afirmações relativamente à inexistência de preconceito de raça no país, ainda que, desta vez, com o intuito de contestá-las ou revê-las (Maio, 1997). Fernando Henrique Cardoso (1955), em resenha da monografia de Thales de Azevedo (1955) sobre as elites de cor baianas, apresenta críticas ao trabalho de Pierson que se tornariam comuns entre os cientistas sociais da USP após as pesquisas conduzidas por Roger Bastide e Florestan Fernandes em São Paulo (Bastide \& Fernandes, 1951), que sublinhavam tanto a incapacidade do sociólogo norte-americano de reconhecer a existência de um preconceito de cor no Brasil distinto do preconceito de classe quanto a generalização indevida de sua análise da situação racial baiana para 0 restante do país. ${ }^{10}$

Pierson, no entanto, foi mais cauteloso em sua tese, afirmando que a ausência de preconceito de raça não implicava inexistência de "distinções sociais" nem de "discriminação" (Pierson, 1945: 422). Nas conclusões, a hipótese do preconceito é expressa de modo ambivalente: "Existe preconceito no Brasil, mas é preconceito antes de classe que de raça, apesar de estar, até certo ponto, ligado à cor" (Idem: 421, grifo do autor). A afirmação, entremeada por ponderações, ao mesmo tempo que serve para relativizar o peso das tensões advindas da cor, indica que Pierson não ignorava a existência das mesmas. Ela também expressa hesitações que o sociólogo tivera no decorrer do seu trabalho de campo, registradas nos relatórios de pesquisa, como notaram Romo (2010) e Brochier (2011), ao se deparar com situações de conflito que não se encaixavam, de imediato, em seu aparato conceitual. ${ }^{11} \mathrm{~A}$ posição de Pierson se torna ainda mais complexa se considerarmos que ele empregou o termo "preconceito de raça" em um sentido estrito, a saber, para indicar a "atitude social que surge em condições de conflito para auxiliar a manutenção de um 'status' ameaçado", e que não devia ser confundido com atitudes de "aversão", "hostilidade" ou "desigualdade de tratamento" (Pierson, 1945b: 455). Traduzindo uma interpretação particular da experiência racial norte-americana, o conceito parecia deslocado no caso baiano porque os brancos não haviam sido confrontados, durante a abolição, por uma população negra hostil que Ihes representasse uma "ameaça ao [...] próprio 'status'", de modo que os sentimentos de desconfiança, apreensão e ressentimento, constitutivos daquela forma de preconceito, não haviam sido experimentados (Pierson, 1945: 419).

Pierson acentua o caráter lento, cumulativo e não-conflituoso da transformação da sociedade de castas baiana em uma "ordem de competição livre" a fim de explicar por que o preconceito não se manifestava na região à maneira norte-americana. Na comparação com os EUA, há uma discreta valoração positiva do caso baiano, que estaria mais afinado com o receituário liberal-reformador de como deviam ser conduzidos processos de mudança nas 
relações raciais: antecedida por "uma onda de terror [...] que varreu o Sul [americano] depois da revolta dos negros [no] Haiti e das desordens surgidas com a subsequente aniquilação dos brancos [haitianos]", a abolição da escravidão nos EUA havia sido um "episódio da guerra civil" estremecido por "um programa de 'reconstrução' imposto por conquista armada [pelo Norte abolicionista contra o Sul escravocrata]" (Idem: 418-419). Não tendo sido gestada desde dentro, crescendo vegetativamente, a mudança de status do negro no Sul americano havia se processado de modo abrupto, mediante uso da força, fomentando ressentimentos e um fundo de memórias entre os brancos que conferiam conteúdo fortemente negativo às representações em torno dos negros.

A interpretação de Pierson da experiência norte-americana, que lhe era mais imediata e familiar, foi uma importante referência em sua avaliação da situação racial brasileira, o que Ihe rendeu a acusação de etnocentrismo (Cardoso, 1955). Mas tais comparações recorrentes, ao invés de indicarem um viés de origem inconsciente, foram um expediente explicitamente empregado pelos sociólogos de Chicago, fazendo mesmo parte de sua compreensão do que significava fazer ciência. Por buscarem extrair regularidades e lições gerais das diversas "histórias nacionais" de contato racial, seus esquemas interpretativos acabavam por ressaltar sistematicamente as diferenças e os contrastes, que se tornavam os elementos valorizados na coleta do material empírico. São ilustrativas deste modo de proceder as orientações que Redfield e Park transmitiram a Pierson ainda quando este dava os primeiros passos em sua etnografia. Nas palavras de Redfield, Pierson devia se ater "somente àqueles fatos que [fossem] relevantes no desvendar das características da situação racial local que são únicas". ${ }^{12}$ Deste modo, a mobilidade vertical que existia historicamente na Bahia, implicando reconhecimento social dos indivíduos de cor, além da possibilidade de associação íntima com as elites brancas, acabou sendo um dos elementos principais explorados por Pierson no esforço de tornar inteligível a "situação racial baiana" porque ela não apresentava semelhança nem com a situação da classe média negra norte-americana, que apenas ascendia nos limites de uma comunidade negra fortemente endogâmica, nem com a condição dos estratos intermediários e biologicamente mestiços da sociedade indiana, fechados sobre si mesmos e socialmente desautorizados a galgar outras posições. Se esta hipótese veio a se tornar plausível para Pierson, isto se deveu, em grande medida, aos marcos interpretativos "autorizados" estabelecidos por Oliveira Vianna e Gilberto Freyre acerca da história social brasileira, que contribuíram para afastar as incertezas cognitivas eventualmente suscitadas por um complexo e contraditório contexto etnográfico.

Ademais, a visão de Pierson acerca do presente da cidade de Salvador depende de projeções implícitas em sua análise, que decorrem dos pressupostos axiológicos do esquema 
classificatório de Park. Ao invés de afirmar a inexistência de obstáculos de cor, Pierson os enxerga como resíduos da antiga ordem escravocrata, em uma atitude claramente otimista. O sociólogo julgava ser questão de tempo até que, com base na ascensão de um contingente cada vez maior de indivíduos de cor, a composição étnica das classes na Bahia se alterasse em direção a uma distribuição menos desigual - distribuição esta que refletiria, eventualmente, a existência de posições sociais baseadas exclusivamente no "mérito individual" e em "circunstâncias favoráveis" (Pierson, 1945: 422), e não mais na "ascendência racial", "condição que escapa ao [...] controle do indivíduo" (Idem: 399).

Neste sentido, a Bahia de Pierson se aproximava dos ideias liberais de uma ordem social meritocrática, com distinções, desigualdades e conflitos considerados naturais a toda forma de sociedade (Idem: 422), mas que não chegavam a comprometer, como era o caso do preconceito racial nos EUA, a possibilidade de realização da democracia enquanto igualdade de oportunidades e livre competição. Este horizonte político se explicita nos relatórios de pesquisa de Pierson, quando este ensaia a análise da situação racial baiana a partir do par conceitual "casta" e "classe": "O corpo de relações sociais [...] peculiar a Índia, Estados Unidos e Brasil respectivamente não constitui tipos diferentes de casta, mas diferentes organizações sociais que, para efeitos de análise esquemática, podem ser concebidas como ocupando posições variadas ao longo de um gradiente cultural, cujo um dos polos pode ser denominado 'casta', e o outro (por falta, talvez, de um termo melhor) 'democracia pura'". ${ }^{13}$ Embebida no imaginário político da época, a Bahia que emerge do trabalho de Pierson é fruto de um jogo de espelhos e contrastes com imagens de diversas regiões do globo, como o Deep South americano, a Índia e o Havaí, de tal maneira que ela somente ganha contornos definidos em sua análise à luz destas aproximações e distanciamentos.

\title{
CONSIDERAÇÕES FINAIS
}

\begin{abstract}
$\mathrm{A}$ s conclusões do estudo de Donald Pierson sobre a Bahia estiveram conjugadas a uma série de observações sobre as tensões e os conflitos entre negros, brancos e mulatos que permeavam a sociedade baiana assim como as adversidades enfrentadas pela população negra, observações que por vezes colidem com suas teses mais gerais. Ainda que o sociólogo seja otimista ao chamar a atenção para a lenta e contínua transição de uma ordem de castas para uma ordem de livre competição em Salvador, sua leitura, informada por um paradigma sociológico universalista (Villas Bôas, 1998), não deixa de registrar a maneira desigual como os grupos raciais se inseriam na estrutura de classes da sociedade baiana. Isso fica evidente na rica etnografia presente em sua obra, que merece ser revisitada.
\end{abstract}


Da mesma forma, uma visão ampliada do trabalho de Pierson que não perca de vista o contexto histórico em que foi produzido deve ir além das molduras nacionais a partir das quais a produção sociológica do passado tem sido geralmente analisada, no Brasil e alhures, atentando para as circunstâncias transnacionais que presidiram sua elaboração, marcadas pela circulação de atores e ideias entre diferentes partes do globo. 0 estudo do sociólogo reúne, mediante nexos intrincados, elementos oriundos de diferentes contextos, como o esquema analítico da Sociologia das relações raciais de Robert Park, então em vias de internacionalização, as inquietações políticas quanto aos destinos da democracia nos EUA e ao lugar de suas "minorias raciais", assim como as interpretações do Brasil elaboradas por intelectuais brasileiros. A análise transnacional da obra de Pierson, ao mesmo tempo que constitui um desafio, é fundamental se quisermos obter uma ampla compreensão de seus significados.

\section{NOTAS}

1 Criada em 1917 por Sears Roebuck, empresário do ramo de vendas por correspondência, a Fundação Rosenwald financiou, nos anos 1920 e 1930, ações em educação e saúde destinadas à minorar as precárias condições de vida dos trabalhadores negros do Sul dos EUA assim como pesquisas que deveriam nortear políticas para o desenvolvimento da região (Chapoulie, 2001: 308-310).

20 caso de Andrew Lind é ilustrativo de como a carreira e as pesquisas de Pierson podem ser situadas em amplo contexto transnacional. Sob orientação de Park, Lind realizou, em fins dos anos 1920, pesquisa sobre o domínio territorial de sucessivas etnias no Havaí, considerado, como o Brasil, uma sociedade "multirracial".

3 Em carta a Robert Redfield, Pierson afirma: "Meu entendimento era o de que, além do estudo na Bahia, eu devia explorar as possibilidades de estudos posteriores aqui sobre contacto cultural e racial, descobrir o que já havia sido feito ou estava em curso nesse sentido, contactar os mais importantes intelectuais brasileiros interessados em nosso campo de estudos e repassar essas informações". Carta de Donald Pierson a Robert Redfield, 1/11/1935. 2p. Fundo Donald Pierson, Arquivo Edgar Leuenroth, UNICAMP (a partir de agora, FDP). Pasta 62. Em carta posterior, Pierson relata o interesse de Anísio Teixeira, então à frente da Secretaria de Educação do Distrito Federal, em promover intercâmbio entre professores da Universidade do Distrito Federal, criada em 1935 como parte de seu programa de reestruturação do ensino público no Rio de Janeiro, e da Universidade de Chicago. Carta de Donald Pierson a Robert Park, Robert Redfield e Louis Wirth, 8/11/1935. $2 f$. FDP, Pasta 62. 0 conteúdo destas e das demais cartas que se seguem foi traduzido livremente.

4 É o que se depreende de carta enviada por Robert Park a Oliveira Vianna em 1935, anunciando a viagem de Pierson ao Brasil: "Fiquei [...] satisfeito em saber que você ficou realmente interessado na possibilidade de um intercâmbio com professores americanos, o que, eu posso lhe contar, é algo que a Universidade de Chicago está agora seriamente considerando. [...] Chamei a atenção dos membros do nosso Seminário de Raça e Cultura para os seus ensaios muito interessantes sobre os aspectos populacionais e raciais da vida cultural no Brasil. [...] Permita-me dizer que eu fiquei bastante impressionado com o caráter do país e do povo e com os recursos ilimitados do Brasil durante minha estadia aí, e que eu tenho verdadeiro interesse em promover relações culturais mais íntimas entre o meu próprio país e o seu [...]". Carta de Robert Park a Oliveira Vianna, 5/2/1935, 2f. Correspondência, Casa de Oliveira Vianna. 
5 Entre estas obras, destacam-se: Populações meridionais do Brasil, de Oliveira Vianna, e Casa grande \& senzala, de Gilberto Freyre. Carta de Donald Pierson a Isaac Goldberg, 30/10/1934. FDP, Pasta 61. 1f. Pierson fez ainda o levantamento da bibliografia em língua inglesa, como o artigo Brazil, laboratory of civilization, de Rüdiger Bilden (Pierson, 1945).

6 A correspondência de Pierson com representantes do governo americano em fins dos anos 1930 e início dos anos 1940 evidencia seus esforços para a obtenção de apoio para a pesquisa e o intercâmbio acadêmico. Em carta a Charles Thomson, então chefe da Divisão de Relações Culturais do Departamento de Estado, Pierson relata suas atividades após o primeiro ano de residência em São Paulo, mencionando alunos brasileiros que the pareciam elegíveis para bolsas de estudo nos EUA. Carta de Donald Pierson a Charles Thomson, 30/12/1940, 4f. FDP, Pasta 3.

7 Carta de Robert Park a Donald Pierson, 11/2/1936, FDP, Pasta 62. 5f, p. 3.

8 Mais recentemente, Romo (2010) chamou a atenção para o descompasso entre a argumentação de Pierson, por um lado, e o registro etnográfico detalhado de declarações abertamente racistas e do quadro de acentuadas desigualdades raciais, por outro. Não concordamos com a autora, entretanto, quando sugere que, no esquema explicativo de Pierson, a ausência relativa de tensões raciais decorre do caráter estático de uma sociedade pouco afeita à mudança. Embora Pierson qualifique a Bahia como uma sociedade tradicional, importava-Ihe, sobretudo, sublinhar o gradualismo de suas mutações, como aquele que vinha presidindo a passagem de uma ordem de castas para uma ordem de classes, gradualismo que é implicitamente valorizado pelo sociólogo na medida em que esposa, ao lado de seus pares de Chicago, uma visão liberal-reformadora para o "problema racial", como indicaremos a seguir.

9 Guimarães (1996a), em que pese a análise acurada das inconsistências na abordagem piersoniana e 0 reconhecimento de seu forte registro classista, por meio do qual "casos de discriminação racial são descaracterizados enquanto tais e reinterpretados como formas de discriminação de classe" (p. 150), atém-se mais ao enquadramento conceitual que informa o trabalho analítico do sociólogo do que aos resultados de sua rica etnografia. Ao fim e ao cabo, a construção de Pierson, de uma "sociedade multirracial de classes", sustentaria teoricamente a visão disseminada acerca da existência de uma "democracia racial" no país (p. 145).

10 Atento aos sentidos que a obra de Pierson veio a assumir no Brasil, Brochier (2011) buscou realizar a importante tarefa de compreendê-la em suas intenções e concepções originais, explorando alguns dos nexos do estudo do sociólogo com a perspectiva de Park. Neste movimento, todavia, o autor tendeu a naturalizar as posições metodológicas e epistemológicas de Pierson, sem se perguntar por suas raízes históricas e políticas, além de subapreciar as componentes intelectuais brasileiras que atuaram na elaboração de sua tese.

11 Nas palavras de Pierson: "Amigos baianos que anteriormente me asseguravam que no Brasil não existia preconceito estão agora, a partir de um contato mais íntimo, começando a reconhecer que tal descrição é apenas teórica, que, em realidade, eles não aceitam o negro em um plano de completa igualdade social". Carta de Donald Pierson a Robert Park, Robert Redfield e Louis Wirth, Report No. 3, 19/6/1936. FDP, Pasta 62. 5f, p.1. E ainda: "É [...] provavelmente seguro afirmar que na Bahia não existe tal coisa como preconceito de raça no sentido em que este termo é usado nos Estados do Sul [dos EUA]. Entretanto, [...] eu não estou ainda certo de que se pode afirmar que o preconceito que de fato existe é preconceito de classe ao invés de ser de casta e que a escala das distinções raciais, incluindo o negro na base e o branco no topo, corresponde em geral simplesmente à escala das distinções de cor existente entre a minoria negra nos Estados Unidos; que aqui não existe casta baseada em raça, mas que existem apenas classes. Isto pode ser verdadeiro, mas precisa de validação posterior. Carta de Donald Pierson a Robert Park, Robert Redfield e Louis Wirth, Report No. 6, 19/12/1936. FDP, Pasta 62. 6f, p.6. 
12 Carta de Robert Redfield a Donald Pierson, 9/12/1935. FDP, Pasta 62. 2f.

13 Carta de Donald Pierson a Robert Park, Robert Redfield e Louis Wirth. Report No. 6, 19/12/1936. FDP, Pasta 62, p. 5. 6f.

\section{REFERÊNCIAS BIBLIOGRÂFICAS}

AKYRA, Iriye. The rise of global and transnational history. Journal of Transnational American Studies, v. 5, n. 1, p. 2-19, 2013.

BASTIDE, Roger \& FERNANDES, Florestan. O preconceito racial em São Paulo. Instituto de Administração da Faculdade de Ciências Econômicas e Administrativas da Universidade de São Paulo. Publicação n. 118, abril de 1951.

BRAM, Joseph. Book Review. Negroes in Brazil: a study of race contact at Bahia. American Anthropologist, v. 46, p. 543-545, 1944.

BRASIL JR., Antônio da Silveira. Passagens para a Teoria Sociológica: Florestan Fernandes e Gino Germani. Tese de Doutorado. Programa de Pós-Graduação em Sociologia e Antropologia. Universidade Federal do Rio de Janeiro, 2011.

BROCHIER, Christophe. De Chicago à São Paulo: Donald Pierson et la sociologie des relations raciales au Brésil. Revue d'Histoire des Sciences Humaines, Publications de la Sorbonne, Paris, 2011, p.293-324.

BULMER, Martin. The Chicago School of Sociology - Institutionalization, Diversity, and the Rise of Sociological Research. Chicago: The University of Chicago Press, 1984.

CARDOSO, Fernando Henrique. Resenha. As elites de cor. Anhembi, São Paulo, v. 19, n. 55, p. 121-124, 1955.

CHAPOULIE, Jean M. La tradition sociologique de Chicago (1892-1961). Paris: Éditions du Seuil, 2001.

CLAVIN, Patricia. Defining Transnationalism. Contemporary European History, v. 14, n. 4, p. 421-439, 2005.

COSTA, Sérgio. Desprovincializando a Sociologia: a contribuição pós-colonial. Revista Brasileira de Ciências Sociais, v. 21, n. 60, p. 117-134, 2006.

COULON, Alain. A Escola de Chicago. São Paulo: Papirus, 1995.

EUFRÁSIO, Mário. Estrutura urbana e ecologia humana. São Paulo: Editora 34, 1999.

FREIRE JUNIOR, Olival; SILVA, Indianara. Diplomacia e ciência no contexto da Segunda Guerra Mundial: a viagem de Arthur Compton ao Brasil em 1941. Revista Brasileira de História, v. 34, n. 67, p. 181-201, 2014.

GUIMARÃES, Antônio Sérgio Alfredo. Cor, classes e status nos estudos de Pierson, Azevedo e Harris na Baia: 1940-1960. In: MAIO, M. C \& SANTOS, R. V. Raça, ciência, sociedade. Rio de Janeiro: Fiocruz, p. 282-294, 1996a.

. O projeto Unesco na Bahia. Colóquio Internacional "O Projeto Unesco no Brasil: uma volta crítica ao campo 50 anos depois". Salvador, Bahia, julho de 2004. Disponível em: http://www.fflch.usp.br/sociologia/ asag/0\%20Projeto\%20UNESCO\%20na\%20Bahia.pdf. Acesso em: 10/2/2017.

HASENBALG, Carlos. Entre o mito e os fatos: racismo e relações raciais no Brasil, Dados, v. 38, n. 2, p. $355-$ $374,1995$. 
HEILBRON, J.; GUILHOT, N.; JEANPIERRE, L. Toward a transnational history of the Social Sciences. Journal of The History of the Behavioral Sciences, v. 44, n. 2, p.146-160, 2008.

LIMONGI, Fernando. A Escola Livre de Sociologia e Política. In: MICELI, S. (org.). História das ciências sociais no Brasil, v. 1, São Paulo: Sumaré/ Fapesp, p. 217-233, 1989.

MAIA, João Marcelo E. A sociologia periférica de Guerreiro Ramos. Cadernos CRH, v. 28, n. 73, p. 47-58, 2015.

MAIO, Marcos Chor. A história do Projeto Unesco: estudos raciais e ciências sociais no Brasil. Tese de Doutorado (Ciência Política). Rio de Janeiro, Instituto Universitário de Pesquisas do Rio de Janeiro (luperj), 1997.

— ; OLIVEIRA, Nemuel da Silva; LOPES, Thiago da Costa. Donald Pierson e o Projeto do Vale do Rio São Francisco: cientistas sociais em ação na era do desenvolvimento. Dados,v. 56, n. 2, p. 245-284, 2013.

MULCAHY, Kevin. Cultural Diplomacy and the Exchange Programs: 1938-1978. The Journal of Arts Management, Law, and Society, v. 29, n. 1, p. 7-28, 1999.

PARK, Robert E. \& BURGESS, E. W. Introduction to the Science of Sociology. Illinois: University of Chicago Press, 1921.

PIERSON, Donald. Por que eu vim à Bahia. Revista da Faculdade de Direito da Bahia, Salvador, v. 11, p. 8993,1936 .

. Um mestre da ciência social. Revista do Arquivo Municipal, São Paulo, v. 76, ano 7, p. 165-168, 1941.

Robert E. Park: sociólogo pesquisador. Sociologia, São Paulo, v. 6, n. 4, p. 282-294, 1944.

. Brancos e pretos na Bahia. Estudo de Contacto Racial. Brasiliana. Biblioteca Pedagógica Brasileira. Rio de Janeiro: Campanha Editora Nacional, 1945.

Teoria e pesquisa em Sociologia. São Paulo: Melhoramentos, 1945b.

. Algumas atividades no Brasil em prol da Antropologia e outras ciências sociais. In: CORRÊA, Mariza. História da Antropologia no Brasil (1930 - 1960). Testemunhos: Emilio Willems e Donald Pierson. Campinas: Unicamp, p. 30-116, 1987

RAJ, Kapil. Beyond Postcolonialism... and Postpositivism. Circulation and the Global History of Science. Isis, n. 104, p. 337-347, 2013.

ROMO, Anadelia. Brazil's living museum: race, reform, and tradition in Bahia. North Cartolina University Press, 2010.

SANSONE, Lívio. Estados Unidos e Brasil no Gantois: o poder e a origem transnacional dos estudos Afro-brasileiros. Revista Brasileira de Ciências Sociais, São Paulo, v. 27, n. 79, 2012.

SECORD, James A. Knowledge in transit. Isis, n. 95, p. 654-672, 2004.

SILVA, Isabela O. P. De Chicago a São Paulo: Donald Pierson no mapa das Ciências Sociais. Tese de Doutorado (Antropologia). São Paulo, Programa de Pós-Graduação em Antropologia Social da Faculdade de Filosofia, Ciências e Letras (Universidade de São Paulo), 2012.

SIVASUNDARAM, Sujit. Sciences and the Global. On Methods, Questions, and Theory. Isis, n. 101, p. 146-158, 2010.

THELLEN, David. The nation and beyond: transnational perspectives on United States history. Journal of American History, v. 86, p. 965-975, 1999. 
TYRRELL, lan. Reflections on the transnational turn in United States history: theory and practice. Journal of Global History, v. 4, n. 3, p. 453-474, 2009.

VALLADARES, Licia do Prado (org.). A Escola de Chicago - Impacto de uma tradição no Brasil e na França. Rio de Janeiro: IUPERJ, 2005.

A visita de Robert Park ao Brasil, o "homem marginal" e a Bahia como laboratório. Caderno CRH, v. 23, n. 58, p. 35-49, 2010.

VILA NOVA, Sebastião. Donald Pierson e a Escola de Chicago na Sociologia Brasileira: entre humanistas e messiânicos. Lisboa: Coleção Vega Universidade, 1998.

VILLAS BÔAS, Glaucia. Leitura proibida: a Sociologia brasileira e a questão racial na década de 30. In: VILLAS BÔAS, Glaucia (coord.). Territórios da língua portuguesa: culturas, sociedades, políticas. Rio de Janeiro: IFCS-UFRJ, p. 115-120, 1998. 